\title{
Prospects for a Truth-Conditional Account of Standing Meaning
}

Forthcoming in R. Schantz ed. Prospects for Meaning, Oxford: OUP.

Guy Longworth

University College London/Warwick University

\section{Introduction.}

Should a theory of meaning for expressions (i.e. types) in a natural language - a theory of standing meaning ${ }^{1}$ for that language - take the form of a theory of truthconditions for sentences of the language ${ }^{2}$ The ubiquity of context-sensitivity-i.e. variation in the truth-conditions of what is stated by the use of a piece of language induced by variation in the circumstance of that use-has appeared to many to undermine an affirmative answer to that question. ${ }^{3}$ Since an expression can make different contributions to the truth-conditions of what is stated by its use despite constancy in its standing meaning, an invariant satisfaction-condition cannot capture its standing meaning. However, even if context-sensitivity forces us to forgo the most straightforward form of truth-conditional account of standing meaning, it may yet be possible to defend a broadly truth-conditional account. The question dividing friend and foe of the truth-conditional account becomes the following: should a theory of standing meaning for sub-sentential expressions take the form of a theory about how the contributions made by sub-sentential expressions to the truth-conditions of things

\footnotetext{
${ }^{1}$ Standing meaning is the context-invariant meaning of expression types.

${ }^{2}$ I shall use talk of truth-conditional accounts of standing meaning as an umbrella for the variety of more specific accounts that seek to account for the standing meanings of sentences by appeal to the conditions in which those sentences would be used to state something true or false. Such accounts include Davidson inspired accounts of standing meaning given by appeal to interpretive theories of truth like that presented in Larson and Segal (1995). Although I shall frame particular proposals in a Davidson inspired form, the general discussion is not bound to that format and analogues of the particular proposals I shall consider can easily be reproduced within alternative semantic frameworks.

${ }^{3}$ The main current proponents of the view that the ubiquity of context-sensitivity threatens the thesis that standing meaning should be given by appeal to truthconditions are, in philosophy, Charles Travis and, in linguistics, Dan Sperber and Deirdre Wilson. See e.g. Sperber and Wilson (1986); Travis (1981), (1989), (1998), (2000). Context-sensitivity also plays a role in motivating Noam Chomsky's animus to truth-conditional accounts of meaning. See e.g. Chomsky (2000). The most important earlier proponents are Austin and Wittgenstein, whose work influences that of many current proponents. See e.g. Austin (1962); Wittgenstein (1953).
} 
stated by the use of sentences are determined in particular contexts? The question has recently been the subject of a great deal of attention, much of it concerning the details of the sorts of semantic and syntactic theories that might sustain an affirmative answer. However, attention to the details has not yet resolved the issue. In the present essay, I shall attempt to step back from some of the details and explain an elementary challenge that must be faced by the defender of a broadly truth-conditional account of standing meaning if their favoured account is to cope adequately with contextsensitivity. The challenge is to provide a justification for such an account that goes beyond its ability to attain extensional adequacy-i.e. its ability to provide correct statements of the contributions made by sub-sentential expressions to the truthconditions of what may be stated in particular contexts by the use of those expressions.

I shall proceed as follows. In the next section I shall consider, and find wanting, a recent attempt by Jason Stanley to motivate a truth-conditional treatment of standing meaning by providing examples of sentences that are invariantly used to make statements that have (or determine) the same truth-conditions. This will also serve as an illustration of the ubiquity of context-sensitivity. In section 3, I'll briefly sketch a minimal account of context-sensitivity on which it is not the responsibility of standing meaning. The purpose of the sketch is to motivate the question how the departures from the minimal account that are recommended by the proponent of a broadly truth-conditional account might be motivated. Then, in sections 4 and 5, I'll develop the elementary challenge facing the proponent of the broadly truthconditional account. In section 4, I'll consider an extreme form of context-sensitivity the existence of which has been emphasised in particular by Donald Davidson. ${ }^{4}$ That form of context-sensitivity is obviously not to be accounted for by appeal to a broadly truth-conditional account of standing meaning. Nevertheless, an extensionally adequate account of that form can be provided. It follows that such an account is not justified merely by its capacity to attain extensional adequacy. In section 5, I'll consider what more is required and argue that there is, at present, no reason to think that additional requirements can be met. ${ }^{5}$

\footnotetext{
${ }^{4}$ See especially Davidson (1986/2005).

${ }^{5}$ I shall not consider alternative responses to apparent context-sensitivity according to which it is merely apparent. Such responses emphasise the important distinction between the standing meaning of an expression and its contribution to what can be
} 


\section{An attempt to motivate a truth-conditional account.}

People use bits of language in order to say (or state) things that are up for assessment as true or false depending upon whether the way things are said (or stated) to be are the way things are. ${ }^{6}$ In that sense, at least, language is involved with truth-conditions. It should also be agreed that when people use bits of language in order to say (or state) things, what they say (or state) often depends upon the standing meanings of the bits of language that they use. It should therefore be agreed that the standing meanings of bits of language often play an important role in determining truthconditions, at least by playing an important role in sustaining things with truthconditions: what people say (or state) by using those bits of language. However, we do not have to stray far from those thin starting points before agreement lapses.

Consider, for instance, the opening passage of a recent paper by Jason Stanley in which he seeks to isolate some data that might form a neutral explanatory target:

Consider an utterance of the sentence 'Some philosophers are from New York'. If no philosopher in the world comes from New York, competent speakers of English know that it is false. They also know that this utterance is true if six philosophers in the world come from New York. In other words, competent speakers have clear intuitions about the conditions under which what is said by an utterance of this sentence is true or false. $(2005: 221)$

Stanley claims that providing an explanation of such intuitions is the task of a semantic theory-i.e., a theory of standing meaning. Stanley's data concern intuitions about arbitrary utterances of the English sentence in (1):

stated by its use and treat standing meaning as determining a satisfaction-condition independently of its role in sustaining what it stated. See e.g. Cappelen and Lepore (2005). From the present perspective, the main difficulty facing such accounts is that they forfeit the motivation for a truth-conditional treatment of language supplied by the role of language in sustaining what obviously has (or determines) truth-conditions, namely what speakers state by using bits of language.

${ }^{6}$ I shall use 'say' and its analogues in what is sometimes called their illocutionary sense, so that saying something is (typically) a way of stating it. As a reminder of this, I'll usually add 'or state'. For present purposes, I shall leave open whether there are other ordinary uses of 'say', for instance a locutionary use. 
(1) Some philosophers are from New York.

His claim is that competent speakers of English know a condition in which each utterance of (1) is false and a condition in which each utterance of (1) is true. (More carefully, the claim ought to be that what competent speakers know concerns the truth-conditions determined by what speakers say (or state) by the use of (1), but I shall sometimes follow Stanley in speaking of utterances as true or false.) In effect, then, Stanley's claim is that competent speakers have clear intuitions about at least some aspects of the truth-conditions of the sentence in (1). Moreover, he seems to assume that the unbiased will accept this claim as characterising some features of English speakers' competence with (1) that any account should aim to explain. ${ }^{7}$

\footnotetext{
${ }^{7}$ Two other examples of sentences that appear to some theorists to have at least partly invariant truth-conditions have been offered in the literature. (See e.g. Szabó (2001), from which the following examples are taken.) The first sort of example involves mathematical sentences, like (i):
}

(i) Two is an even number.

It is plausible that this sort of sentence has invariant truth-conditions (or, more carefully, is used to make statements that determine the same truth-conditions in all contexts). But it is plausible that the reason for this is their abstract subject matter. Indeed, there is some plausibility to the view that such sentences are not really parts of natural language proper but rather are parts of scientific language. Either way, there is no reason to suppose that they supply a good model for the semantic treatment of sentences used to speak about sublunary matters. The second sort of example involves chemical classifications, as in (ii):

(ii) The ring is gold.

Although the truth-conditions for (ii) vary with context, it has been claimed (e.g. by Szabó) that what is said by any use of (ii) would be true if the described ring was chemically pure gold. Again, we might accept this claim, but suggest that such cases arise only for scientific language and not within natural language. But in fact the claim is not obviously right. Consider, for instance, the following case. George is collecting impure gold jewellery in order to smelt it down and acquire the pure gold that it contains. Kim knows this, but utters (ii) to George in describing a chemically pure gold ring that she has found for him. Kim intends George to recognise that she has said something relevant to completion of his task. Plausibly, George and Kim can both be brought to accept that what Kim has said is false. (They may both also recognise that, in other contexts, the same form of words could have been used to say something true in describing the same ring. But that is not relevant to the truthconditions of what Kim in fact said.) Finally, even if there is a minimal contextinvariant sufficient condition on the use of (ii) in order to state truths, or a minimal 
Stanley goes on to indicate the shape that he thinks should be taken by an account of those features of English speakers' competence. The account he proposes is one according to which knowledge of the meanings of English expressions is knowledge of the contributions those expressions make to the truth-conditions of what sentences in which they participate can be used to say (or state) - e.g. knowledge of the satisfaction-conditions of those expressions. If Stanley's claim about (1) were obviously acceptable, then his suggestion about the form such an account should take would be plausible. We would have been provided with a reason to expect that at least some components of speakers' linguistic competence might be accounted for by viewing them as possessing knowledge of the contributions made by expressions to the truth-conditions of (what speakers say by) uses of sentences. Moreover, we would have been provided with reason to think that the satisfaction-conditions of at least some English expressions are stable across different circumstances of use. And that result could then be used as a basis for the construction of a more nuanced account able to capture the standing meanings of expressions whose satisfaction-conditions vary across circumstances - i.e. expressions subject to context-sensitivity.

Suppose that we assume at the outset only the following: (a) what speakers say (or state) determines truth-conditions and (b) mutual knowledge of the standing meanings of the expressions that they use often play a role in determining what they say (or state). What we are looking for is reason to think that standing meanings should be characterised in terms of truth-conditions. If at least some expressions invariably were used to say things with the same truth-conditions, then we would have some reason to think that the source of the truth-conditions of what they were used to say could be traced to their standing meanings. Hence, if Stanley's claim were acceptable, we would have some reason to think that standing meanings for at least those expressions should be given in terms of their contributions to the truthconditions of sentences in which they participate.

However, there are a variety of reasons for thinking that the unbiased will not—or should not - accept Stanley's claim. Let's assume that Stanley's claims about the conditions in which utterances of (1) are true or false are made by the use of (2) and (3) in a particular context (e.g. at a particular philosophy conference).

context-invariant necessary condition, it does not follow that there are not additional sufficient or necessary conditions that are context-sensitive. 
(2) No philosopher in the world comes from New York.

(3) Six philosophers in the world come from New York.

Against that background, one concern with Stanley's claim is that the standing meaning of (1) fails to fix an understood domain of quantification for 'Some philosophers'. Of course, a competent speaker of English would typically possess the sort of background knowledge that would make it obvious that the understood domain should include all and only Earth-bound philosophers. But that knowledge appears to go beyond knowledge of the standing meaning of 'Some philosophers'. It seems perfectly consistent with the standing meaning of (1) that it should have been used at a detention centre for troublesome philosophers situated on Mars. In that context, (1) might be used in order to say something that competent speakers of English would take to be true just in case (as I would put it in this context) (4):

(4) Some philosophers on Mars come from New York.

And assuming that all philosophers from New York have been interred in the Martian detention centre, what a speaker would say by uttering (1) and (2) would both then be true while what they would say by uttering (3) would be false.

A second concern is the following. The conditions under which what speakers say by uses of ' $X$ are philosophers' is true of some individuals appear to be taken by competent speakers of English to vary with variations in the context of use. For instance, in a context where the topic of discussion was a comparison of the intellectual lives of people from New York with that of people from Paris, what a speaker would have said by an utterance of (1) might be taken to be true iff (as I would put it in this context) (5):

(5) Some persons who think deeply come from New York.

Now suppose that in the context in which (2) and (3) were uttered-i.e. a particular philosophy conference - some individuals satisfy what is said by a use of ' $X$ are philosophers' iff the individuals are employed as academics in Philosophy departments. What a speaker said by an utterance of (1) made in the comparison-with- 
Paris context might be true, what they said by a conference-utterance of (2) also true, and what they said by a conference-utterance of (3) false; alternatively, what a speaker said using (1) and (2) might be false while what they said using (3) is true. ${ }^{8}$

I don't mean to suggest that Stanley is insensitive to either type of concern. Indeed, he has done much to bring to philosophical consciousness the impact of variations in context upon the truth-conditions of what speakers say (or state) by uttering particular sentences in those contexts. The present point is just that the effects of such variations are more widespread and more potent than is sometimes noticed. In particular, it is far from clear that there is a core of cases where competent speakers' intuitions about truth-conditions are impervious to information about variations in context. Since even concerted attempts to isolate such cases are apt to fail, contextsensitivity appears to be ubiquitous. Hence, it is far from clear that we have any immediate reason to favour a truth-conditional account of the standing meaning of any sentence. As a corollary, no evidence has been provided that there is a range of expressions with context-invariant satisfaction-conditions that can be put to use in providing satisfaction-conditional constraints on the context-variant satisfactionconditions of other expressions. ${ }^{9}$

What we are looking for is reason to think that an account of standing meaning should be given in terms of truth-conditions. And we have just seen that the most straightforward sort of reason is unavailable: the fact that what speakers use expressions to say (or state) have (or determine) truth-conditions provides no

\footnotetext{
${ }^{8}$ This particular example of variation might be thought to be due to something akin to ambiguity or polysemy, and so to variations in the standing meaning with which the expression ' $X$ are philosophers' is used. That is more clearly the wrong treatment for other examples. Suppose that one standing meaning of the expression is used solely to speak of professional philosophers. Answers to the following questions will then depend upon the particular contexts in which the expression is used. Do individuals who are employed in law departments, but who spend a significant portion of their time writing for philosophy journals, satisfy a use of the expression to speak of being a professional philosopher? How much time should they spend on writing for philosophy journals so to count? Would it suffice that they have had a single paper published in a philosophy journal? Would it suffice that they have written a single paper and submitted it for publication? Would it suffice that they have written a paper with the intention of submitting, or half such a paper, or thought about writing such a paper? If they have published one or more papers, must they be in journals that only publish philosophy?

9 See also Cappelen and Lepore (2005). They argue for the following conditional: if the arguments typically offered in favour of context-sensitivity are compelling, then they are compelling with respect to more or less every expression.
} 
immediate support for the thesis that standing meaning determines truth-conditions. One way of proceeding would be to attempt to provide a less straightforward reason for giving a truth-conditional account of standing meaning. However, I am unaware of any plausible attempt to pursue that line. ${ }^{10}$ A second way of proceeding would be to argue that the optimal account of what is agreed to bear truth-conditions - the things speakers say (or state)—would be what I shall call a meaning-based account. According to such an account, the standing meaning of an expression determines the way that the satisfaction-conditions of what can be said by its use are determined in context. The model here is standard treatments of indexical or demonstrative expressions, like 'here' or 'those'. If it were viable, such an account could be used to sustain the thesis that standing meanings can be characterised by appeal to their roles in determining satisfaction-conditions in context. The second way of proceeding is the target of the remainder.

\section{Competing explanations for context-sensitivity.}

What are the sources of context-sensitivity? On the assumption that people use language in order intentionally to say (or state) things, a minimal hypothesis would be that one major source is variation in the communicative intentions with which people speak (or variation in the communicative intentions with which they reasonably can be taken to have spoken) in different contexts. Since our primary interest in peoples' uses of language (at least in practical contexts) concerns what they are thereby saying (or stating), it is to be expected that our intuitions about examples are driven to a large extent by our responsiveness to what we would take a speaker to be saying (or stating) in a particular context by the use of words with particular standing meanings. And since the things people say (or state) have truth-conditions, it is to be expected that we will have intuitions about those truth-conditions. It remains to be seen why we might expect those intuitions to vary with variations in the context in which a speaker uses language in order to say (or state) something.

To a first approximation, communicative intentions are intentions to perform illocutionary acts - e.g. intentions to say that such-and-such, to state that such-andsuch, or to warn that such-and-such. Such intentions are reflexive, being in part speakers' intentions that their possession of those very intentions be recognisable by

\footnotetext{
${ }^{10}$ However, see Cappelen and Lepore (2005) for some relevant discussion.
} 
an audience. It is because of this feature that a speaker succeeds in their intention to perform a particular type of illocutionary act - e.g. to say that such-and-such-if (and, perhaps, only if) their intended audience recognises them to have performed that type of act. And it is also because of this feature that we should expect variations in context, broadly conceived, to impact upon what speakers can reasonably intend to say in a given context. In general, one can reasonably act on an intention to $\phi$ only if, to a first approximation, one lacks grounds for thinking it impossible that one should (thereby) succeed in $\phi$-ing. Hence, one can reasonably act on a communicative intention to $\phi$ that such-and-such only if, to a first approximation, one lacks grounds for thinking it impossible that one's audience will recognise that one has acted on that intention. And whether one lacks such grounds will depend upon whether one can reasonably expect to be understood as one intends by an audience with access to what one can reasonably take to be mutually accessible information.

Three major sources of information that an audience will typically be in a position to exploit are the following. First, the audience can exploit what they take to be standing mutual knowledge. Second, they can exploit what they take to be mutual knowledge about the specific context in which the speaker has spoken, including the current direction and aims of the conversation, salient objects, the speaker's demonstrations, and the fact that the speaker has intentionally uttered words with a particular meaning in order to communicate. Third, they can exploit what they take to be mutual knowledge about the words that the speaker has used, in particular about the standing meanings of those words. Let's suppose that that list is exhaustive and that a speaker has uttered some words the standing meanings of which are mutually known by speaker and audience. For the speaker to have reasonably intended to say (or state) that such-and-such by the use of those words, it must be reasonable for the speaker to expect their audience to be in a position to recognise what they have said (or stated). Hence, it must be reasonable for the speaker to expect their audience to be in a position to exploit mutual knowledge both of a standing and a context-bound sort in order to figure out what the speaker has said. Since the speaker can rely upon mutual knowledge about context in making their intentions known to an audience, typically they will rely upon such knowledge. But now it is to be expected that, holding fixed mutual knowledge of the standing meanings of the words that the speaker used, the illocutionary acts that the speaker can reasonably expect to be 
recognised as performing will shift with variations in context. That is so for the simple reason that what the speaker can reasonably expect their audience to make out about their communicative intentions on the basis of context-bound mutual knowledge will vary as the present context, or the content of (what is taken to be) mutual knowledge about the present context, varies. ${ }^{11}$

The materials used in the foregoing sketch of an explanation for contextvariance are to be found (more or less) amongst our thin agreed starting points: speakers often say (or state) things-i.e. things that determine truth-conditions-by exploiting the standing meanings of the bits of language that they use. (The small addition to the agreed starting points is that speakers often do this by also exploiting mutual knowledge of things other than standing meanings. An alternative addition would be that standing meanings fail to determine truth-conditions so that speakers are forced to rely upon meaning-additional information in presenting and discerning (things with) truth-conditions.) For that reason, it is the minimal or default hypothesis about how instances of variance in truth-conditions are to be explained.

However, an alternative, broadly truth-conditional explanation for at least some cases of variance has been proposed. According to the alternative meaningbased explanation, the standing meanings of affected expressions carry specific directions about how context-bound information (and perhaps information about the standing background) is to be exploited in determining the communicative intentions with which they are used. To a first approximation, this involves treating the standing meanings of all expressions that are subject to context-sensitivity as if they are (or cooccur with) demonstratives or indexicals and so, as on standard treatments of the latter, embody instructions for determining the contributions that they make to truthconditions in particular contexts. ${ }^{12}$ On that type of account some cases that appear on initial inspection to involve speakers and their audiences exploiting information that is

${ }^{11}$ It follows that on this account one cannot say (or state) just anything in any context by the use of words with a particular standing meaning. Whether one is in a position to say a particular thing on a particular occasion depends upon whether the three sources of information suffice to make one's communicative intentions accessible to an audience. Hence, it is no objection to the account that there are genuine constraints - even meaning-based constraints - on what one can say with words with particular standing meanings in a range of contexts. For an attempt to use the existence of such constraints in support of a meaning-based account of variation, see Stanley (2002).

${ }^{12}$ See e.g. Segal and Rothschild (ms), Stanley (2000), (2005), Stanley and Szabó (2000), and Szabó (2001) for accounts of this sort. 
not determined (even in context) by the standing meanings of the expressions they use are not in fact of that sort. Rather, some such cases involve meaning-directed exploitation of additional information, wherein the types of additional information and the ways that it conditions what a speaker can say in a given context are specified by the standing meanings of their words. According to the alternative explanation, the standing meaning of an expression might be given by characterising the instructions that it embodies concerning the determination of satisfaction-conditions on the basis of information about the context of utterance.

It is worth noting that the alternative explanation is not immediately ruled out by the nature of the explanatory target. As Kent Bach has emphasised, what must ultimately be determined is the content of the illocutionary act(s) that a speaker has performed. But since facts about the standing meanings of expressions do not determine speakers' communicative intentions, standing meanings cannot determine the content of their illocutionary acts. In principle, expressions with particular standing meanings can be used with an enormous variety of communicative intentions. Hence, even if the content of an illocutionary act coincided on occasion with the content determined by the standing meanings of the expressions used in that act, the fact that they coincided would not be determined by the expressions' standing meanings. ${ }^{13}$ However, it does not follow that the standing meaning of an expression does not constrain what is said by the use of the expression. And in the absence of information that is not determined by standing meaning-e.g., information about context-the content of a speaker's communicative intentions might even be constrained to uniqueness by the standing meanings of the expressions they use. The ubiquity of context-sensitivity appears to make it impossible that in such circumstances a speaker could reasonably intend their audience to discern determinate truth-conditions. ${ }^{14}$ But if it were possible for the speaker reasonably so to intend, their doing so would provide cases where the standing meanings of the expressions used determined the truth-conditions of what was said by their use. And the proponent of a meaning-based account of variance in truth-conditions holds that contextual effects on truth-conditions are typically mediated by standing meaning. They will therefore hold that standing meaning is responsible for much of the role of meaning-additional information in determining truth-conditions. Hence, they will hold that cases in which

\footnotetext{
${ }^{13}$ See e.g. Bach (2005), (2007).

${ }^{14}$ See e.g. Travis (1994).
} 
further information is available to influence what is said, over and above information brought into play by standing meaning, are (at best) rare. For the vast preponderance of cases, they will hold that the (truth-conditional) content of what is said (or stated) can be discerned just by following the instructions for the exploitation of contextual information embodied in standing meaning.

Although the meaning-based explanation carries some additional commitments, it is very similar to the default explanation. Both explanations hold that audiences are typically required to draw on information over and above their knowledge of the standing meanings of expressions in order to make out what a speaker has said (or stated). And in order that both explanations underwrite the same (or similar) results with respect to what speakers are taken to have said (or stated), it is plausible that the ways in which they see audiences as drawing on additional information will have to be rather similar. In particular, both accounts will make appeal to speakers' communicative intentions in their respective accounts of the fixation of (the truth-conditions of) what speakers' say (or state). It is therefore a nice question what might induce us to forgo the minimal explanation for any particular case in favour of the meaning-based explanation. In the next two sections, I shall consider whether any support for the meaning-based explanation is provided by its capacity to attain extensional adequacy.

\section{Davidson and context-sensitivity.}

Davidson has attempted to argue that mutual knowledge of standing meaning is inessential to linguistic communication. In pursing that aim, he presents cases in which a speaker's communicative intentions are recognisable despite the fact that their intentions are not constrained by the standing meanings of the expressions that the speaker employs. I agree with Davidson that mutual knowledge of standing meaning is inessential to some instances of linguistic communication. However, I shall present an account of the way expressions' satisfaction-conditions are determined in context that is able to cope with cases of the sort that Davidson presents. The upshot is that, despite its extensional adequacy, that form of account is inadequate. A secondary purpose of the discussion is the discernment of requirements on a more adequate account. In section 5., one such requirement will be employed in the development and assessment of a meaning-based account of cases of variance in (the truth-conditions of) what is said (or stated). 
Let's begin by following Davidson in specifying the explanatory target a little more precisely. A particular sentence can be used to perform an illocutionary act with any content. To take a well-worn example, in suitable circumstances the sentence 'Jones has neat handwriting' can be used to inform an audience that Jones is not a good candidate for an academic position. It is therefore implausible to expect a straightforward account of the contribution of expression meaning to just any illocutionary act that can be performed by the use of a sentence. Following Davidson, we shall take the target of explanation to be our ability to discern the most basic element in the system of illocutionary acts that can be performed by using language. Davidson calls this element first meaning, and offers the following characterisation:

The intentions with which an act is performed are usually ordered unambiguously by the relation of means to ends ... Thus the poet wants (let us say) to praise the beauty and generosity of his patron. He does this by using mages that say the person addressed takes on every good aspect to be found in nature ... He does this in turn by using the word 'tire' to mean 'attire' and the word 'foison' to mean 'harvest'. The order established here by 'by' can be reversed by using the phrase 'in order to'. In the 'in order to' sequence, first meaning is the first meaning referred to ...

Suppose Diogenes utters the words 'I would have you stand from between me and the sun' (or their Greek equivalent) with the intention of uttering words that will be interpreted by Alexander as true if and only if Diogenes would have him stand from between Diogenes and the sun, and this with the intention of getting Alexander to move from between him and the sun, and this with the intention of leaving a good anecdote to posterity. Of course, these are not the only intentions involved; there will also be the Gricean intentions to achieve certain of these ends through Alexander's recognition of some of the intentions involved. Diogenes' intention to be interpreted in a certain way requires such a self-referring intention, as does his intention to ask Alexander to move. In general, the first intention in the sequence to require this feature specifies the first meaning. (1986/2005: 92)

In brief, then, the first meaning carried by a speaker's use of a piece of language is the content of the first illocutionary act in the 'in order to' sequence (or the last in the 'by' 
sequence). Davidson adds that, in order to restrict first meaning to linguistic meaning, the first meanings of utterances must be systematically related, in accord with relations amongst the words and structures of sentences used in making of the utterances. When the latter condition is met, it is plausible that we can apportion responsibility for aspects of the first meaning of an utterance amongst the words and structures of the sentence used in making it. I shall assume that meeting the latter condition requires that speakers' illocutionary intentions bear upon sub-sentential expressions, so that we can speak of the first meanings with which speakers use subsentential expressions on particular occasions.

Having characterised first meaning, Davidson seeks to argue for (amongst other things) the following hypothesis. Mutual knowledge of the standing meanings of expressions - i.e. knowledge of the meanings of expression types, conceived as prior to and independent of any particular occasion of speech-plays no essential role in audience's abilities to make out what a speaker first meant by the use of those expressions. Davidson's argument is based upon the possibility of extreme variations in the first meanings that speakers can accord their acts of speaking. Davidson points to the fact that it is possible, in suitable circumstances, to intend to use-and to be understood as intending to use - a piece of language to say things that are not supported by what would be taken by competent speakers to be the standard standing meanings of those pieces of language. His favourite examples involve malapropismfor instance, a speaker's use of the sentence 'We're all cremated equal' in order to first mean that we are all created equal. But he holds that cases where a speaker's illocutionary intentions are unsupported by the standard meanings of the words that they use, and yet they are still understood by their audience, are commonplace. Since cases of that sort are possible — indeed, on Davidson's view, widespread — knowledge of standing meaning is inessential to convergence on first meaning by a speaker and their audience. As Davidson puts it,

... the theory we actually use to interpret an utterance is geared to the occasion ... The reason for this is ... perfectly obvious: a speaker may provide us with information relevant to interpreting an utterance in the course of making the utterance. (101) 
What we are left with then is the view that, as Davidson puts it, '... linguistic ability is the ability to converge on a passing theory [i.e. a systematic view of occasional first meaning that one shares, on occasion, with one's interlocutor] from time to time ...'. And Davidson is pessimistic about the prospects for a serious theory of this ability, at least to the extent that a serious theory would be required to characterise a set of rules, or regularities, governing it:

... there are no rules for arriving at passing theories, no rules in any strict sense, as opposed to rough maxims and methodological generalities. A passing theory really is like a theory at least in this, that it is derived by wit, luck, and wisdom from a private vocabulary and grammar, knowledge of the ways people get their point across, and rules of thumb for figuring out what deviations from the dictionary are most likely. There is no more chance of regularising, or teaching, this process than there is of regularising or teaching the process of creating new theories to cope with new data in any field - for that is what this process involves. (107)

Let's look at Davidson's argument in a little more detail. Consider (6).

(6) Some philosophers are from New York.

Now consider two cases in which (6) is used in order to first mean something. In the first, Kim is the speaker. Kim knows the (standard) English meaning of (6), and relies upon mutual knowledge of that meaning in using (6) in order to communicate something to an audience. If we ignore for the moment other contextual effects, we can assume that Kim first means to say something that is true iff (7):

(7) Some philosophers are from New York.

In the second case, George is the speaker. George, by contrast with Kim, does not intend to rely upon mutual knowledge of the (standard) English meaning of (6). Instead, George has somehow made it clear to his audience that he is using ' $X$ are philosophers' so that it is satisfied by some things just in case they are (as I would put 
it, using standard English) philologists. ${ }^{15}$ Hence, again ignoring other contextual effects, George first means something that is true iff (8):

(8) Some philologists are from New York.

Whether or not such cases are as widespread as Davidson suggests, they surely are possible. The question Davidson seeks to press is the following. How should we account for the abilities of audiences in either case to discern the truth-conditions determined by the speakers' first meanings? In particular, what, if any, role should be accorded the audiences' knowledge of the (standard) English meaning carried by (6)?

If one thought that the standing meanings of expressions are given in terms of context-invariant satisfaction-conditions, then one would have reason to doubt that the audiences' knowledge of standing meaning plays the same role in both cases. Since the satisfaction-conditions determined by what is first meant by uses of the target expression vary across the two cases, knowledge of a single satisfaction-condition for the expression could not suffice to determine what it is possible for the speaker to first mean by its use in both of those cases. And it is difficult to see what role knowledge of the satisfaction-conditions for ' $X$ are philosophers' required by the truth-conditions given in (7) could play in enabling an audience to figure out the satisfactionconditions for that expression that are required by the truth-conditions given in (8). In particular, it is plausible that someone who lacked that knowledge would be as well placed to discern George's first meaning as someone who possessed it.

If one thought that standing meanings are given in some other way, then it would be somewhat less obvious that the same knowledge of meaning could not help the audiences to figure out the truth-conditions of the speaker's first meaning in both cases. And lacking a clear account of another way in which standing meanings might be given, and might feed into the determination of first meaning, the proposal is difficult to assess. But it is plausible that someone who lacked what we would intuitively take to be prior knowledge of the (standard) English meaning of ' $X$ are philosophers' would be as well placed to discern George's first meaning as someone

\footnotetext{
${ }^{15}$ Plausibly, some cases of the required sort might involve reliance upon knowledge of the partial phonetic similarity of the word 'philosopher' and the word 'philologist', together with knowledge of the standing meaning of 'philologist'. I shall assume that the case discussed in the text is not of that sort.
} 
who possessed that knowledge. So it is implausible that knowledge of (standard) standing meaning, as ordinarily conceived, plays a role in the second case.

Prima facie, the prospects seem dim for an account of Davidson's cases according to which the standing meanings of the words in (6) determine what can be first meant by its use. In particular, the prospects appear dim for an account according to which the standing meanings of expressions are a matter of the contribution they make to the truth-conditions of sentences in which they participate and where the latter truth-conditions determine (the truth-conditions of) what may be first meant by the use of those sentences. However, if we are willing to lower our sights somewhat, and require of an account of the standing meaning of expressions only that it provide a contextually invariant statement of how the contribution those expressions make to sentential truth-conditions gets determined in particular contexts, then it is possible to provide such an account. Consider, for instance, the following preliminary account of the standing meaning of ' $X$ are philosophers' (with initial universal closure suppressed, $X$ a plural parameter, and $\boldsymbol{Y}$ a predicate parameter):

(9) If $u$ is an utterance involving ' $X$ are philosophers', and the speaker $s$ of $u$ first means ' $X$ are philosophers' to be true of (or satisfied by) individuals $X$ iff $\boldsymbol{Y}(X)$, then $X$ satisfies ' $X$ are philosophers' iff $\boldsymbol{Y}(X)$.

Except that (9) involves predicative quantification, it is formally analogous to standard truth-conditional treatments of plural demonstrative expressions like 'those', as in the simplified axiom in (10):

(10) If $u$ is an utterance involving 'those', and the speaker $s$ of $u$ first means 'those' to refer to $X$, then 'those' refers to $X$.

Hence, it should be obvious that (9) is (or can be amended to be) formally satisfactory. And (9) can interact in the usual way with axioms governing other expressions and combinatorial machinery in order to deliver conditional statements of truth-conditions for whole utterances. ${ }^{16}$ So, in conjunction with the presumption that

\footnotetext{
${ }^{16}$ It is worth noting that truth-theoretic theorems delivered on the basis of (9) may fail to be interpretive, due to the role of predicative quantification. For instance, if 'water' and ' $\mathrm{H}_{2} \mathrm{O}$ ' are co-extensional, then the predicate quantification involved in an
} 
the truth-conditions determined by what a speaker can first mean by the use of a sentence coincide with the truth-conditions of that sentence, (9) supplies an account of the standing meaning of ' $X$ are philosophers' able to play a role in determining first meaning in both our target cases (and, of course, all other cases). The proposal therefore has at least four virtues. First, it supplies a context-invariant account of the standing meaning of ' $X$ are philosophers'. Second, it does so in a way that is formally adequate. Third, it does so in a way that feeds into the most straightforward account of the projection from sub-sentential meanings to sentential truth-conditions. And fourth, the account is (trivially) extensionally adequate. ${ }^{17}$

If (9) supplied an adequate treatment of the contribution ' $X$ are philosophers' makes to the first meanings of utterances of sentences in which it participates, then we would have a working model for a general response to the cases that Davidson presents. Although those cases would continue to make it plausible that the standing meaning of the expressions that they involve cannot be given by appeal to contextinvariant satisfaction-conditions, they would not show that a satisfaction-conditional account of the standing meanings of those expressions could not be given. In

analogue of (9) for 'water' would deliver theorems that failed to distinguish between e.g. the interpretive (i) and the non-interpretive (ii):

(i) 'The sample is water' is true iff the sample is water.

(ii) 'The sample is water' is true iff the sample is $\mathrm{H}_{2} \mathrm{O}$.

For discussion of a related issue that arises with respect to ordinary indexicals and demonstratives, see Higginbotham (2002) and Gross (2005).

${ }^{17}$ The proposal also appears to fit a conception of semantics proposed by Stanley (drawing on King and Stanley (2005)):

The semantic content of a sentence relative to a context is derived by taking the semantic contents of the parts of that sentence, relative to that context, and composing them in accord with the composition rules governing the syntactic structure of that sentence. The semantic value of a basic constituent of a sentence is what is determined by speaker intentions together with features of the context, in accord with the standing meaning of that lexical item. (2005: 226)

Moreover, the proposal appears to sustain what Stanley calls semanticism:

Given this conception of semantics, the position of the semanticist is then that the source of our intuitions about the truth or falsity of utterances relative to various possible circumstances is due to semantics. (226) 
particular, they would fail to show that the standing meanings of those expressions could not be accounted for via an account of how their satisfaction-conditions are determined in context. However, I take it to be obvious that (9) is not an adequate treatment of the standing meaning of ' $X$ are philosophers'.

The main reason why (9) is not an adequate treatment of the standing meaning of ' $X$ are philosophers' is that knowledge of (9) provides almost no information about the first meaning with which that expression may be used. (Plausibly, it supplies no information that is not already provided by knowledge of the expression's logicosyntactic powers.) Someone who knew (9), and attempted to use it in order to figure out the truth-conditional contribution of a use of ' $X$ are philosophers', would be just as much reliant on 'wit, luck, and wisdom' as someone who attempted the same task in ignorance of (9). And that would be the case whether or not the speaker who used ' $X$ are philosophers' in order to first mean something did so in the expectation that they and their audience shared mutual knowledge of (9). But, at least in situations where a speaker relies on mutual knowledge of standing meaning, we expect the possession of such knowledge to aid an audience in the task of discerning first meaning. Hence, (9) is inadequate as an account of the standing meaning of ' $X$ are philosophers', and cannot provide a model for the treatment of other expressions for which analogous variations in first meaning are possible. Put another way, if (9) and its ilk were the best that we could offer in response to the sort of case that Davidson presents, then we ought to be as pessimistic as Davidson about the possibility of providing a substantive account of the role of standing meaning in the discernment of first meaning in cases of that sort.

The main purpose of the foregoing discussion of Davidson has been to indicate that a context-invariant account of expression meaning can cope with even the most extreme form of context-sensitivity. If we are willing to accept an insubstantial account of standing meaning, as per (9), then we can (more or less) write extensional adequacy into the clauses of that account. The critical failing of such an account is that it fails to supply an account on which knowledge of standing meaning can play a role in sustaining audiences' abilities to make out what a speaker has said, even in cases where speakers aim to exploit their audiences' knowledge of that standing meaning.

\section{Can there be an adequate meaning-based account of context-sensitivity?}


In ordinary cases, audiences can figure out what a speaker has said (or stated) by using at least three sorts of information: (i) mutual knowledge of standing meaning; (ii) mutual standing background knowledge; and (iii) mutual knowledge about the specific context in which the particular speech act takes place (including the fact that the speaker has attempted to communicate by uttering expressions with particular standing meanings). In the sort of case considered in the previous section audiences are forced to rely only upon (ii) and (iii), so that they are required to figure out what the speaker has said without making use of their knowledge of standing meaning (or their expectations about mutual knowledge of standing meaning). In this section, I return to the sort of case supposed to be captured by the meaning-based account, instances of which involve audiences drawing on (i) in such a way that what they take a speaker to have said by the use of an expression with a particular standing meaning varies with variation in information about (ii) and (iii). Drawing on the discussion in the previous section, I'll indicate why broadly truth-conditional accounts of that sort of case are required to take a particular form so impose upon their proponents a particular justificatory burden.

In the earlier discussion of Stanley's attempt to motivate a truth-conditional account of standing meaning we considered two cases of the second sort. Those cases involved two ways in which competent English speakers' views about the truthconditions of what a speaker says (or states) by using (11) vary with variations in the context in which that use takes place, despite appearing to competent speakers to exploit the same standing meanings.

(11) Some philosophers are from New York.

The first instance involved variations in understood restrictions on the domain of quantification for 'Some philosophers'. In some possible contexts, what a speaker said (or stated) by using (11) would be true iff some philosophers on Earth are from New York. In other possible contexts, what a speaker said with (11) would be true iff some philosophers at the interdisciplinary conference at which (11) was uttered are from New York. In yet other possible contexts, what a speaker said with (11) would be true iff some philosophers on Mars are from New York. The second instance involved variation in the satisfaction-conditions for the expression we would 
ordinarily represent as ${ }^{18}$ ' $X$ are philosophers' that is induced by variation in what the speaker first meant by the use of that expression. There are possible contexts where the expression can be used in order to first mean something that is true of individuals iff (as I can put it in this context) they are full-time members of teaching or research faculty in departments labelled 'Philosophy' by institutional administration. There are other possible contexts where it can be used to first mean something that is true of individuals iff (as I can put it in this context) they engage in some of the activities associated with teaching or research in departments that are so-labelled. And so forth. I shall focus here on the second instance of variation, that attending ' $X$ are philosophers'. 19

As was noted above, the sort of variation at issue here differs in a critical respect from that involved in the sorts of case that Davidson presents. The critical difference is that the present cases involve speakers and their audiences exploiting the standing (standard) meaning of the expressions they use, the former in order to publicise, and the latter in order to discern, speakers' first meaning. An adequate account must capture that difference. Hence, the sort of thin account of the meaning of ' $X$ are philosophers' that we considered when discussing Davidson, repeated here as (12), is not adequate.

(12) If $u$ is an utterance involving ' $X$ are philosophers', and the speaker $s$ of $u$ first means ' $X$ are philosophers' to be true of (or satisfied by) individuals $X$ iff $\boldsymbol{Y}(X)$, then $X$ satisfies ' $X$ are philosophers' iff $\boldsymbol{Y}(X)$.

As before, (12) is both formally and extensionally adequate: it delivers the right results about the satisfaction-conditions with which ' $X$ are philosophers' is used and does so in a way that can feed into a standard compositional account of what may be said by the use of larger expressions in which ' $X$ are philosophers' participates. However, the fact that (12) is able to capture the sorts of variation in satisfactionconditions involved both in Davidson's cases and in the cases now at issue shows that it provides an inadequate treatment of the latter cases. Hence, the fact that an

\footnotetext{
${ }^{18}$ I use the qualification 'we would ordinarily represent as' in order to leave open that a proper treatment of sentences involving the target expression might involve additional unarticulated elements.

${ }^{19}$ I leave open whether the first instance should be treated as a special case of the second. See e.g. Stanley and Szabó (2000).
} 
extensionally adequate account can be given of the way that an expression's satisfaction-conditions are determined in context does not entail that an adequate account of the standing meaning of an expression can be given in that form. Rather, as we saw in the discussion of Davidson's cases, an account of the standing meaning of an expression should do more than merely capture the satisfaction-conditions that uses of the expression sustain in different contexts. For achieving that much is a (more or less) trivial matter. In addition, an adequate account should attain extensional adequacy in a way that reveals how standing meaning can be exploited in order to figure out those satisfaction-conditions. At the very least, such an account must include an account of elements of standing meaning that are accessible to audiences prior to their discernment of a speaker's first meaning and so can aid audiences in their attempts to make out that first meaning. A replacement for (12) that is better able to meet that condition is given in (13):

(13) If $u$ is an utterance involving ' $X$ are philosophers', and the speaker $s$ of $u$ exploits mutual knowledge of the standing meaning of ' $X$ are philosophers' in order to first mean it to be true of (or satisfied by) individuals $X$ iff $\boldsymbol{Y}(X)$, then $X$ satisfies ' $X$ are philosophers' iff $\boldsymbol{Y}(X)$.

However, for at least two reasons (13) will not do. The first reason is that (13) is supposed to supply an account of the standing meaning of ' $X$ are philosophers' but cannot do so because it appeals to mutual knowledge of that standing meaning in characterising the way that the target expression's satisfaction-conditions are determined. A way past that difficulty would be to have the speaker exploit part of what is mutually known about the standing meaning of the expression in order to first mean it to bear a satisfaction-condition. The combination of partial standing meaning and first meaning publicised through exploiting partial standing meaning could then be used by audiences in order to make out the first meaning with which the expression is used. The second reason why (13) will not do is that it makes unanalysed appeal to the standing meaning of its target expression. In order to participate in an account of standing meaning given in terms of contributions to truth-conditions, the account must be given solely in terms of the way that satisfaction-conditions are determined in context. A way past the second difficulty would be to have the speaker exploit mutual knowledge of a necessary condition on satisfaction in first meaning what they do. 
Audiences can then exploit the partial satisfaction-condition determined by standing meaning in order to discern the first meaning through which full-blown necessary and sufficient condition are determined. Putting the two amendments together, we get (14), with ' $X$ are philosophers ${ }^{*}$ ' standing in for a statement of the requisite condition:

(14) If $u$ is an utterance involving ' $X$ are philosophers', and the speaker $s$ of $u$ exploits mutual knowledge that ' $X$ are philosophers' is true of $X$ (or satisfied by $X$ ) only if $X$ are philosophers $*$ in order to first mean it to be true of (or satisfied by) individuals $X$ iff $[X$ are philosophers $* \& \boldsymbol{Y}(X)]$, then $X$ satisfies ' $X$ are philosophers' iff [X are philosophers $* \& \boldsymbol{Y}(X)]$.

A variety of more specific accounts have been offered in place of (14). For instance, according to one more specific account ' $X$ are philosophers' itself makes a stable contribution to the determination of truth-conditions for sentences in which it participates, but that those sentences invariably involve additional unpronounced elements whose satisfaction-conditions are fixed by speaker's communicative intentions as per the condition ' $\boldsymbol{Y}(X)$ ' in (14). According to other more specific accounts, ' $X$ are philosophers' itself carries an unpronounced element with the same function, or is itself a contextually-sensitive element akin to a form of indexical or demonstrative. ${ }^{20}$ But for present purposes we can take (14) to be the most general form that is instanced by more specific accounts of this form that have been offered.

The proposed account involves two main deviations from the inadequate (12). The first deviation is in the component condition, schematised with ' $X$ are philosophers*', that must be met by individuals if they are to satisfy what is first meant by uses of the target expression. The second deviation is a condition determined by what is first meant in accord with the first condition, given meaningadditional information, and that supplies full-blown necessary and sufficient conditions on satisfaction. In order to demonstrate that the proposed account is not merely a notational variant of the inadequate (12), the putative deviations from (12)

${ }^{20}$ See e.g. Segal and Rothschild (ms), Stanley (2000), (2005), Stanley and Szabó (2000), and Szabó (2001) for more specific accounts of these sorts. Some of these accounts accord full responsibility for contextual variation in satisfaction-conditions to an unpronounced element. Accounts with that feature can give a disquotational satisfaction-condition for (e.g.) the expression ' $X$ are philosophers' absent the unpronounced element, instead of running the dog leg via ' $X$ are philosophers*'. 
must be spelt out in more detail. In particular, such a development would be required to spell out the condition schematised by ' $X$ are philosophers ${ }^{*}$ ' in (14) and then to explain how mutual knowledge of that condition feeds into the determination of the condition ' $\boldsymbol{Y}(X)$ '. As far as I know, the defenders of analogues of (14) have not yet fulfilled either obligation. And until more detail is provided, we will not be in a position properly to evaluate the proposal. Hence, we cannot yet determine whether or not an adequate account of the standing meaning of such expressions can be given on the basis of an account of the determination of the satisfaction-conditions their uses acquire in particular contexts. Absent the provision of such detail, proposals like (14) are apt to appear plausible only due to the trivial form of extensional and formal adequacy that their schematic formulations share with (12).

The major challenge attending the present type of proposal is to distinguish sharply between that type of proposal and the type instanced in (12). Put another way, the challenge is to show that the present type of proposal is able to register the difference between the sort of case that Davidson emphasises and the more commonplace cases where standing meaning is exploited to say (or state) different things - i.e. to say (or state) things with different truth-conditions - in different contexts. Put a third way, the challenge is to do more than restate what appeal to standing meaning is supposed to aid in explaining: the way that competent speakers are able to exploit their knowledge of standing meaning together with meaningadditional information in order to figure out what speakers have said (or stated). It is a simple matter to give formally adequate accounts that sustain variance in first meant truth-conditions. What needs to be shown is that those accounts are able to capture the ways that standing meaning feeds into the discernment of first meaning.

Although we are not in a position properly to evaluate such proposals we can briefly consider the prospects of a more developed account. I shall focus upon the challenge of providing a specification of the condition ' $X$ are philosophers ${ }^{*}$ ' that is able to play the sort of role it is required to play in an adequate development of (14). A minimal desideratum here is that the proposal must make plausible that competent speakers have access to that condition in advance of making out the satisfactionconditions of what is first meant by uses in context. The difficulty is that there appears to be no evidence that the desideratum is met.

Consider, for instance, the earlier discussion of Stanley's attempt to motivate a truth-conditional approach to standing meaning. We saw there that even concerted 
efforts to discern necessary conditions on the satisfaction of an expression are apt to fail. And even where such efforts are successful, there is no immediate reason to suppose that their success is underwritten by prior knowledge of the discerned conditions. Success is equally well explained by appeal to our ability to generalise from the context-bound satisfaction conditions that we are able to discern through reflection upon real or imagined uses of an expression.

There is no principled difficulty in providing a sketch of instructions for the determination of the required condition. What is required is a condition met by all individuals that satisfy what can be first meant in at least one possible context by a use of ' $X$ are philosophers' that exploits mutual knowledge of the standing meaning of that expression. In order to follow the instruction, then, we should seek to hold fixed the standing meaning of the expression while considering, for all possible contexts, what it is possible to first mean with the expression in those contexts. However, even if we had a sufficiently good grasp on the range of possible contexts in which standing meaning is exploited that we were able to follow those instructions, our ability to follow the instructions would provide no support for the claim that our knowledge of standing meaning consists, in part, in our knowledge of the revealed conditions. Rather, our ability to follow the instructions would appear to rely upon our prior possession of knowledge of standing meaning.

Might it be argued that our ability to follow the instructions - more generally, to discern the truth-conditions of what is said (or stated) in particular contextsprovides the basis for an inference to the best explanation in support of our possession of knowledge of the conditions? Without much further work, it appears not. For the agreed starting points, according to which standing meaning can play a role in determining what a speaker first means by the use of an expression, and what a speaker first means determines a satisfaction-condition, already guarantee that we should be able to use the instructions in order to determine the required conditions. ${ }^{21}$ So it is hard to see what explanatory gain would be achieved by explaining that ability by appeal to our prior possession of knowledge of the conditions.

What is required is evidence that competent speakers have access to, or at least cognizance of, the conditions that is prior to their judgements about (the satisfaction-

21 At least that is so modulo the assumptions made in the previous paragraph concerning our grasp on the role of standing meaning and on the range of possible contexts. 
conditions of) what can be first meant by the use of the target expression in particular contexts. I don't wish to rule out the possibility that such evidence might be forthcoming, perhaps on the basis of a developed account of the use of additional information in determining what is first meant. But I do not think that we have any grounds for optimism on that score. Indeed, the fact that competent speakers are often surprised by what may be first meant by the use of a familiar expression in an unfamiliar context provides some grounds for pessimism. ${ }^{22}$

\section{A sceptical conclusion.}

Views that appear initially to involve scepticism about standing meaning typically involve only scepticism about particular accounts of standing meaning. ${ }^{23}$ My aim here has been to develop, in an elementary way, one form of scepticism about broadly truth-conditional accounts of standing meaning. Absent independent reason to think expressions have satisfaction- or truth-conditions, grounds for an affirmative answer depend upon the existence of a tight connection between expressions and things that obviously have, or determine, such conditions: things first meant by speakers. What is wanted, therefore, is reason to think that an account of expressions' standing meanings can take the form of an account of the determination of what can be first meant by the uses of those expressions in different contexts. One way of trying to provide such a reason would be to give an adequate account of that form. However, although an extensionally adequate account can be given, we have seen-through consideration of an analogous treatment of Davidson's cases-that extensionally adequate accounts may yet be inadequate. In addition, an adequate account must be such that knowledge of what it says about the standing meaning of an expression can

${ }^{22}$ It is a commonplace that competent speakers can be surprised by the outputs of their linguistic competence. For instance, competent speakers of English may be surprised to learn that 'I am' cannot always be contracted, so that (i) is unacceptable:

*Kim is going to the party and I'm too.

Hence, no firm conclusions should be drawn from competent speakers apparent ignorance about the required conditions. Determining the bases of competent speakers' judgements remains a difficult and largely empirical project. The present point is only that the patterns of speakers' judgements do nothing to support the view that the outcome of that project will be favourable to a truth-conditional conception of their competence with standing meaning.

${ }^{23}$ See e.g. the discussion of Quine's scepticism in Hylton (2007) and the discussion of Kripke's scepticism in Kusch (2006). 
play the role that is played by knowledge of standing meaning in facilitating the discernment of first meaning. A central challenge facing proponents of such accounts is to make plausible that their favoured account meets that adequacy condition. Unless they are able to meet that challenge, they have provided no reason for optimism about the prospects for even a broadly truth-conditional account of standing meaning.

\section{References.}

Austin, J. L. (1962) Sense and Sensibilia, Oxford: Clarendon Press.

Bach, K. (2005) 'Context ex Machina', in Z. Gendler Szabó ed. Semantics versus Pragmatics, Oxford: Clarendon Press.

Bach, K. (2007) 'Regressions in Pragmatics (and Semantics)', in N. Burton-Roberts ed. Pragmatics, Basingstoke: Palgrave Macmillan.

Cappelen, H. and Lepore, E. (2005) Insensitive Semantics: A Defense of Semantic Minimalism, Oxford: Blackwell.

Chomsky, N. (2000) New Horizons in the Study of Language and Mind, Cambridge: Cambridge University Press.

Davidson, D. (1986/2005) 'A Nice Derangement of Epitaphs', in R. Grandy and R. Warner eds. Philosophical Grounds of Rationality, Oxford: Clarendon Press; reprinted in D. Davidson (2005) Truth, Language, and History, Oxford: Clarendon Press (page references to the reprinted version).

Gross, S. (2005) 'Context-Sensitive Truth-Theoretic Accounts of Semantic Competence', Mind \& Language 20(1): 68-102.

Higginbotham (2002) 'Competence with Demonstratives', Nô̂s, 36 (s16): 1-16.

Hylton, P. (2007) Quine, London: Routledge.

King, J. C. and Stanley, J. (2005) 'Semantics, Pragmatics, and the Role of Semantic Content', in Z. Gendler Szabó ed. Semantics versus Pragmatics, Oxford: Clarendon Press.

Kusch, M. (2006) A Sceptical Guide to Meaning and Rules: Defending Kripke's Wittgenstein, London: Acumen Publishing Ltd.

Larson, R. and Segal, G. (1995) Knowledge of Meaning, Cambridge, Mass.: MIT Press.

Segal, G. and Rothschild, D. (ms) 'Indexical Predicates'.

Sperber, D. and Wilson, D. (1986) Relevance, Oxford: Basil Blackwell.

Stanley, J. (2000) 'Context and Logical Form', Linguistics and Philosophy, 23(4): $391-434$. (2002) 'Making it Articulated', Mind \& Language, 17(1-2): 149-68. (2005) 'Semantics in Context', in G. Preyer and G. Peter eds. Contextualism in Philosophy: Knowledge, Meaning, and Truth, Oxford: Clarendon Press. and Szabó, Z. G. (2000) 'On Quantifier Domain Restriction', Mind \& Language, 15(3): 219-261.

Szabó, Z. G. (2001) 'Adjectives in Context', in R. Harnish and I. Kenesei eds. Perspectives on Semantics, Pragmatics, and Discourse, Amsterdam: John Benjamins. 
Travis, C. (1981) The True and the False: The Domain of the Pragmatic, Amsterdam: Benjamins.

(1989) The Uses of Sense: Wittgenstein's Philosophy of Language, Oxford: Clarendon Press.

_ (1994) 'On Being Truth-Valued', in S. L. Tsohatzidis ed. Foundations of Speech Act Theory: Philosophical and Linguistic Perspectives, London: Routledge.

— (1998) 'Pragmatics', in B. Hale and C. Wright eds. A Companion to the Philosophy of Language, Oxford: Blackwell.

— (2000) Unshadowed Thought, Cambridge, Mass.: Harvard University Press.

Wittgenstein, L. (1958) Philosophical Investigations, G. E. M. Anscombe trans., $2^{\text {nd }}$ edn., Oxford: Basil Blackwell. 